\title{
Learning together, learning deeper: A little teacher assisted learning engagement
}

\author{
Jamina G. Camayang ${ }^{1}$, Romiro G. Bautista ${ }^{2}$ \\ ${ }^{1}$ College of Teacher Education, Quirino State University-Main Campus, Philippines \\ ${ }^{2}$ Office of the University Director for Instruction, Quirino State University-Main Campus, Philippines
}

\section{Article Info \\ Article history: \\ Received Sep 23, 2020 \\ Revised Mar 6, 2021 \\ Accepted Apr 3, 2021 \\ Keywords: \\ Collaborative learning \\ Learning in partnership \\ Little teacher \\ Peer mentoring \\ Pre-service teachers}

\begin{abstract}
Peer mentoring in the dawn of new educational paradigms harnesses the act of becoming an educationist to facilitating learning in a peer mentoring practice. This study explored the opportunities of an emancipatory approach to teaching and learning under the thrust of learning together, learning deeper through the indulgence of little teachers under the peer mentoring scheme of learning. Employing the senior secondary education students (as little teachers), who came from their Student Teaching program from the Department of Education, and the junior secondary education students (as mentees), who enrolled in their Teaching Science in the Secondary Schools under the qualitative research design and phenomenology as point of inquiry, the following were found: Mentors in the mentoring process need to be approachable and accommodating; Mentees in the mentoring process need to be responsible with their learning task coupled with learning initiative; Enjoyable learning encounters, collaborative learning sessions, open and barrier-free communication, and close and rigid supervision through spoon feeding, modelling, and feedback are some of the perceived characteristics of an effective mentoring program; and Readiness of both mentors and mentees hinder the efficacy of the mentoring program. Owing to the results of the study, it is recommended that a formal mentoring program in the College of Teacher Education be institutionalized for it spurs extensive learning.
\end{abstract}

This is an open access article under the CC BY-SA license.

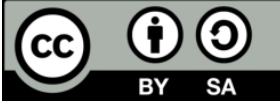

\section{Corresponding Author:}

Romiro G. Bautista

Office of University Director for Instruction

Quirino State University-Main Campus

3411 Diffun, Quirino, Philippines

Email: romiro.bautista@qsu.edu.ph

\section{INTRODUCTION}

Learners of the 21 st century come across their learning opportunities collaboratively with other learners. As prospective teachers, they must internalize their future work and works as educationists. As such, they must win learning experiences in partnership through peer mentoring, managing a functional small group, dialogue, self-reflection, among others. The principle that learning is cooperative and collaborative process must be seeded among them, i.e., cooperation fosters extensive learning - learning together, learning deeper [1]. In doing so, prospective teachers are prompted to direct emancipatory learning experiences which may sharpen their philosophies of teaching and learning. When realized, their indulgence as 'little teachers' will provide them the opportunity to develop authentic responsibility and interdependence as cooperative approaches are always enabling [2], [3].

Peer mentoring is an act of emancipating learning with the indulgence of a little teacher who acts as their mentor in collegial and collaborative learning sessions. Studies revealed that mentors and mentees 
develop an academic relationship vis-à-vis learning goals through modelling and feedback in a dialogic manner. Exposure to this kind of learning engagement spurs the interests of every learner as they transcend to some learning extensions through independent learning and research activities [4]-[6].

The crux is: pre-service teachers as future educationists should make use of cooperative and collaborative approaches as they build a support system in the dynamic cultural activities of teaching and learning. In this way, students are taught to learn to live together and learn deeper which can lead to the development of a community of practice and inquiry of independent learning.

This study explored the experiences of pre-service secondary teachers as little teachers and mentees as a way of enriching their quests of learning together and learning deeper. Specifically, this study sought to: 1) Describe the nature of little teachers in mentoring as perceived by their mentees; 2) Describe the nature of mentees in mentoring as perceived by their little teachers; 3) Capture factors that contributed to the realization of the tasks of little teachers and their mentees; and 4) Identify factors that may hinder the efficacy of the mentoring process.

Transformational learning theory pertains to learning that is influenced by personally relevant experiences, which emerge through social interactions, peer dialogue, and self-reflection. Experiencing transformational learning involves acknowledging one's values, beliefs, and worldviews and critically assessing whether those fixed opinions are functional and true in all contexts. Before transformational learning can occur, a number of essential events need to happen. First, an individual need to critically reflect on an experience, participate in safe but exposed dialogue about the experience, and learn from the views and experiences of others in an emotionally open way [7]. After such reflection, the person cross-examines assumptions and convictions that are deeply rooted within one's psyche. Transformational learning is more fully enabled when educators create a safe communicative learning environment, where students can openly discuss conflicting feelings, thoughts, and past actions [7], [8]. Through experiencing these stages of learning, a student acquires a contemporary, broader comprehension of life. Mezirow [9] pointed out that transformational learning often involves uncomfortable aspects of learning, which may include: 1) Disorientation and confusion; 2) Self-examination of assumptions; 3) Recognition that others are negotiating similar changes; 4) Exploration of new relationships, new roles, and a plan of action; 5) Creation of selfconfidence in new roles; and 6) Integration of a new perspective into one's life. Moreover, he described transformational learning as dichotomously exhilarating and challenging. Mezirow and Taylor [10] added that this reflective-based learning develops "autonomous thinking", a practice where an individual is guided by personal interpretations, rather than idly following the perceptions, judgment, and feelings of family, friends, and teachers.

\section{RESEARCH METHOD}

This study employed the qualitative research design using phenomenology as strategy for inquiry. The informants, where qualitative data were generated, were the pre-service secondary teachers who served as little teachers (mentors) and mentees in an experimental classroom teaching. To be qualified as informants of the study, the mentors and mentees should have finished the mentoring program and learning plans with the mentors as little teachers of the mentees in their actual teaching in the secondary schools. Participants explained their experiences including a configural mode of understanding and principles-the meanings of their stories and experiences as part of an identity development [11].

The proponents prepared the interview guide and it was validated by a researcher whose credibility is beyond compare. Likewise, the proponents personally interviewed the informants to gather the needed data in the study. Before the interview was conducted, the proponents briefed the informants that their participation in the interview is voluntary and they can terminate it anytime. Moreover, they were briefed that their identity will be kept with utmost confidentiality. Transcripts of the interview were carefully transcribed and coded which were validated by a researcher whose credibility is beyond compare. Audit trail was employed in routing the transcripts of the interview among the informants in ascertaining the veracity of their claims. Audit trail is an in-depth approach to illustrating that the transcripts are based on the participants' narratives. It also involved a description on how the data were gathered and analyzed [12], [13]. Henceforth, the data are considered verified and valid.

Moreover, data was analyzed thematically to conclude on the research objectives. Themes were formulated based on the recurring claims of the informants which served as bases in an inquiry-based analysis vis-à-vis the research problem. Aptly, the analyses done in the research includes familiarization and organization, coding and recoding, and summarizing and interpreting [14]. 


\section{RESULTS AND DISCUSSION}

Peer mentoring is an academic activity that builds dynamic, yet reciprocal relationship between mentors and the mentees. This alternative concept of mentoring promotes the development of both mentors and mentees [15]. In this study, mentors are the counterparts of the mentees who have advanced in their studies. Moreover, they are fresh from their Student Teaching program. Aptly, mentors are active partners who help the mentees in maximizing their potentials and achieving their personal and professional goals. The crux is: putting people from the same culture or social upbringing tend to assimilate each other as they find a bond that enhances their self-confidence through time [5], [6], [16]. The following themes were formulated based on the gathered data from the informants' interview. Data were validated through document trail to ascertain the veracity of each claim.

\subsection{Nature of the little teachers}

\subsubsection{Accommodating mentor}

The mentoring environment, just like an ordinary learning climate, must be favorable to all learning conditions. Mentors, in the mentoring process, should help mentees build a network of relationship, provide opportunities for them to collaborate their learning activities, enjoyable sessions that can motivate them to come across their activities, and keep them on track vis-à-vis their learning goals through formative feedback and support system.

In this study, the little teachers (mentors) fostered substantial facilitative acts as cohorts of establishing a conducive learning atmosphere to collaboration. Furthermore, this transcends learning variables and atmosphere that harnesses a culture of learning together and deeper through the More Knowledgeable Others (MKOs). Moreover, their MKOs were their senior fellows in the program who used to be their teammates in most of their activities and acquaintances. Aptly, they are their confidantes whom they have had some prior academic engagements in the past.

In view of Vygotsky's Social Development Theory [17], social interaction plays a central role in the process of building 'meanings'. To him, social learning precedes development. Moreover, the employment of MKOs in the process is paramount to leverage on the cognitive development of the learner. Aptly, learners learn best with their confidantes as they are made to interact freely; hence, learning is optimized. The crux is: putting a mentor close to the proximity and level of the mentees enhances learning.

The following transcripts from the informants qualify the claim of this study that little teachers are accommodating mentors:

\footnotetext{
Mentee 1: “...I was free to ask questions anytime if I have doubts on the agreements that I cannot follow because they (mentors) were very accommodating. I was able to get along with them immediately..."

Mentee 2: "...Mentor G was very accommodating. I was enticed to pursue more so I cooperated $100 \%$. I was motivated because he was too kind; so, I get along with him immediately..."

Mentee 3: "...I enjoyed because my mentors were very accommodating. They were there to support me since we were planning until I executed the demo teaching..."

Mentee 4: "...I benefited very much from the Student Teachers who became my mentors. They were approachable and accommodating although one of my mentors was strict..."
}

The foregoing results contradict the findings of Abegglen, Burns, and Sinfield [5]; Ragavan [16]; Cropper [18] when they said that mentees need time to be with and learn from their mentors. It can be noted that Mentee 2 elucidated well that he gave his $100 \%$ cooperation during the mentoring process although it happened only for a short period of time. Moreover, Mentee 1 claimed that he was able to adjust to his mentors immediately. Unlike in the cases of Abegglen, Burns, and Sinfield [5]; Ragavan [16]; Cropper [18], the mentors and mentees in the current study came from similar locale, familiar with each other, and all of them were peers although the mentors were senior university students while the mentees were junior university students who were majoring in biological science. It was claimed that a mentoring program that falls in the same clout, culture, and specific experience (in the case of the mentor) is most likely to succeed [18], [19]. Moreover, unlike in the cases of Abegglen, Burns, and Sinfield [5]; Ragavan [16]; Cropper [18], the current study needed not to take more time to establish relationships as they belong to the same college and mostly, they were friends. Hall and Jaugietis [20]; Kensington-Miller [21]; and Graven [22] claimed that time is needed to establish a relationship in the mentoring process. The crux is: matching mentors and mentees on the basis of similar interests and demographics enhances the success of the program [16], [21], [23]. Moreover, it will eradicate the issue on time element on the success of the mentoring program which was identified by the previous researchers in this field [5], [6], [16]. 


\title{
3.2. Nature of mentees in a mentoring program
}

The following transcripts from the informants qualify the claim of this study that mentees must be responsible with the initiative to carry out their learning tasks with their mentors.

\subsubsection{Responsible}

Responsibility comes as a virtue of willingness to take charge of their studies: willing to change their assumptions, consider different perspectives, follow through and do the work, accumulate high learning outputs, among others. This concordance of the mentees is likened to a successful mentoring program.

\author{
Mentor 1: “...Mentees must be responsible enough. They need to have the learning initiative \\ to undergo independent study..." \\ Mentor 3: "...Mentees must be responsible to their learning tasks..." \\ Mentor 4: “....Mentees need to study independently; responsible enough to their studies..."
}

Mentors and mentees in the academic mentoring program must come from a shared culture of learning scheme with the mentees (academic protégées) to be as responsible as expected. Hall and Jaugietis [20]; Kensington-Miller [21]; Crisp and Cruz [24]; Leung and Bush [25] articulated that commitment increases the likelihood of attaining a successful mentoring program. Commitment, in this kind of in situ programs, calls for accountability and responsibility between mentors and mentees. The reluctance and mediocrity of the mentees in their learning tasks may soon hamper the mentoring process as claimed by mentors 1,3 , and 4 . The concordances of the mentees may be attributed to the fact that their mentors were their friends and acquaintances in the college.

\subsubsection{Learning initiative}

Learners (mentees, in this study) come across learning with a mental readiness and initiative to undergo cognitive activities. As such, they must be strategic in carrying out every learning task relative to their academic progress. This act among mentees would lead to novel self-discoveries and abundance of knowledge. This cultivates the mentees' self-determined actions, responsibility, and autonomy over their academic growth and development.

In view of Bandura's Social Cognitive Theory [26], self-efficacy is an integral input to the learners' performance attainment. Hence, a directed learning that exudes an expanded interest. Moreover, this enhances experiences that promote personal mastery in the mentoring process. Moreover, the Law of Attitude of Thorndike's Law of Learning elucidates that learning is guided by a total set of attitudes and motivation [27]. Hence, learning is optimized when the learner is set to learn more or to excel better with the learners' internal motivation.

\section{Mentor 1: "...Mentees need to have the learning initiative to undergo independent study..." \\ Mentor 2: "...Mentees need to do advanced studies, research activities..."}

In this study, mentors 1 and 2 stressed out that mentees need to have their initiative in learning so they may advance to their sessions as an extension of their learning. In doing so, they may advance to their topics through independent studies and research activities as suggested by mentor 2 .

\subsection{Characteristics of the mentoring process}

\subsubsection{Enjoyable learning encounters}

One of the characteristics of an effective classroom teaching is varied and enjoyable learning encounters. Learners need to participate in emancipatory activities that will hasten their growth and development vis-à-vis learning plan.

In view of the Transformational Learning Theory [9], the learners (mentees) need to be exposed in varied relationships, new roles, and a plan of action, creation of self-confidence in new roles, and integration of a new perspective into one's life. In this study, they are exposed to varied activities that honed their responsibilities as a team player in a mentoring process which involves modelling and feedbacking as evidenced in the transcripts of the study on supervision. Through reflection, the mentees were exposed to some tasks that require reflective and autonomous thinking which cultivates a community of inquiry among them and eventually a community of practice. Moreover, Mezirow and Taylor [10] described transformational learning as dichotomously exhilarating and challenging as learners are exposed in a practice where an individual is guided by personal interpretations, rather than idly following the perceptions, judgment, and feelings of family, friends, and teachers. 
The following transcripts from the informants qualify the claim of this study that a session led by a little teacher provides enjoyable learning encounters:

Mentor 1: “...I designed varied activities like brainstorming activities so I could get their attention. They enjoyed every session ..."

Mentor 3: "...Like a normal classroom, enjoyment is the key. I provided them enjoyable sessions..."

Mentee 1: "...I enjoyed the coaching and mentoring of my little teachers - from the buzz sessions, planning, up to the mock demonstration. I super enjoyed our sessions. Likewise, my students enjoyed my session, too..."

Mentee 3: "...I enjoyed their pieces of advices especially that I am a first timer to teach HS students. I got a lot of realizations based on their experiences in the field..."

\subsubsection{Collaborative learning sessions}

Cooperative approach in education fosters students' achievement. In fact, there are convincing evidences that cooperative teams achieve higher levels of thought and retain information longer than students who work only as individuals. The shared learning during small-group discussion gives students the opportunity to engage in discussion, take responsibility for their own learning; thus, becoming critical thinkers. Small-group discussion also engenders further thinking since mentees are engaged in activity, reflection, and conversation where they become responsible for defending, proving, justifying, and communicating their ideas to their little teachers [4], [22].

The following transcripts from the informants qualify the claim of this study that a session led by a little teacher provides collaborative learning sessions:

Mentor 1: “...I always solicit their ideas as this is a group work. There is a synergy in a group work - collaborative works..."

Mentor 3: "...of course, they are involved in my sessions. We tried to collaborate all the time..."

Mentee 2: “...I am very much thankful for the full support of my mentors. Our sessions helped me a lot. We did my LP collaboratively. It was superbly good as my LP earned minimal corrections from my professor..."

Mentee 3: “...I enjoyed as my mentors were very accommodating. They were there to assist me - from planning, to coaching until I executed the demo teaching. We did it collaboratively. The good thing about it was the minimal correction of our professor..."

\subsubsection{Communication}

Peer dialogue is used as a potent strategy to implement a learning plan in a bar-none standard as mentors and mentee collaborate with each other through functional groups. The chronotype of Bakhtin's work underscored the importance of dialogue and interaction which supports the idea that learners in groups have the ability to organize and guide their learning activities [28]. Furthermore, learners come to a learning progression in shared-learning conditions under social constructivism [17].

Purportedly, mentees interact professionally and synergistically with their mentors (little teachers) to generate learning plans. This plan is derived from a multi-voice and multi-perspective approach in learning that is inherent in dialogues and interactions with others through social reconstruction which according to Bakhtin [28] is called heteroglossia. This interaction scaffolds mentees' knowledge, skills, and beliefs towards the subject. This is vital as the mentees are novice in teaching: first timers to teach in a formal secondary school class session. Moreover, the mentors (little teachers) are fresh from their Student Teaching who has brought a number of learning experiences from their cooperating schools and teachers in the Department of Education (DepEd).

As mentors and mentees come to a culture of oneness in a culture of inquiry and practice through collaboration, they develop a niche to further enrich their knowledge that boost their morale and confidence to develop every lesson; hence, a better output and outcome. It can be noted that one of the facets of peer mentoring is an avenue for indirect learning by the mentees as teaching is claimed to be a cultural activity.

In view of the Transformational Learning Theory, the mentees learn from the views and experiences of their mentors (little teachers) through dialogic approach about a given experience [7]. In this study, the communication between the little teachers and their mentees is a barrier-free which the informants believed to be the key for the success of their mentoring process. Moreover, it is claimed that an open communication in the mentoring process reciprocally make an interaction tie between the mentor and mentees [24]. 
The following transcripts from the informants qualify the claim of this study that a session led by a little teacher provides effective communication mechanism. The free communication mechanism and absence of barrier led to better outcomes:

- Free communication

Mentor 2: “...They are team players. They kept on clarifying things although I told them to ask me when in doubt..."

Mentor 4: “...It was successful because they kept on clarifying things. I encouraged them to ask questions when in doubt..."

Mentee 1: “...I was free to ask questions whenever I have doubts. They (mentors) were very accommodating..."

Mentee 2: “...My experiences with a Practice Teacher (PT) tandem was fulfilling. It was good because I felt like they were my fellows. This made me inquire freely which was just ok for them..."

Mentee 4: "...I was free to inquire on how to do the plan, on enriching, and executing it. I learned a lot of strategies as they had just finished their student teaching. In fact, my mentor's cooperating teacher was the most outstanding teacher in DepEd..."

- Absence of barriers

Mentor 4: “...They were free to ask questions like there was no barrier (gap) between us..."

Mentor 2: “...my mentees were free to ask questions. I told them that I am their tutor and not their teacher (emphasis is given that there must be no barrier or gap between them)..."

Mentee 1: "...It seems that there was no barrier or gap between us as we were cliques, peers..."

Mentee 3: "...I was free to ask questions like there was no barrier or gap between us. It was good as I did the tasks well..."

\subsubsection{Supervision}

Supervision, as applied in peer mentoring, involves the development of the mentee's confidence, motivation, knowledge, and technical know-how. This exists in a complex relationship that includes paying attention to what is happening between the mentor and mentee. Mentoring (or more accurately, learning) is at the heart of the relationship between the mentor and mentee as they build an academic relation towards a certain academic goal [29], [30].

Purportedly, the mentee's development is not necessarily linear and can involve progressing at varying speeds for different functions and processes. It can also include regression (for example, in confidence) when processes are done unfavorable. On the other hand, the mentor-mentee relationship is influenced by social and organizational contexts within which it occurs [31], [32].

The crux is: peer mentoring distinguishes between training supervision, in which someone undergoes initial professional development for one of the helping professions, and consultative supervision, an arrangement between two qualified persons where one helps the other to reflect on their professional practice (a kind of co-supervision). Trainee supervision, then, may indeed include (or even comprise) an element of overseeing and assessment - as well as collaboration. The supervision of qualified practitioners is more likely to contain a collaborative element [30], [33], [34].

The following transcripts from the informants qualify the claim of this study that a session led by a little teacher provides effective supervision. The close yet rigid mentoring and spoon-feeding strategies led to better outcomes:

- Close supervision

Mentor 2: "...I closely supervised them as they were not attentive. I did modelling and feedbacking and it was effective..."

Mentee 1: "...They did a close supervision. It was effective; so, I was attentive..."

Mentee 3: "...Tutoring is good and I got to understand it better. Employing it in close supervision will surely be a promising strategy for the slow learners. I promise to use it later..."

Mentee 4: “...My mentors made a close supervision to me: one-on-one strategy. I was mentored easily..."

- $\quad$ Rigid supervision

Mentor 3: "...It depends on the mentee - mine was slow, so I mentored hardly - output based. It was rigid and I really demanded quality output..." 
Mentor 4: “...I was a little bit strict in supervising them. I made them realize that we need to do good. The harder I pushed them, the better they responded. It was rigid but I know that I satisfied them..."

Mentee 2: “... They did it rigidly. They made me realize the plan (lesson plan) well..."

- $\quad$ Spoon feeding

Mentor 3: “...Both parties must be ready. Sometimes, they come to me with nothing. So, I got no choice but to spoon-feed them ..."

Mentor 1: “...I really pushed them well. At times, I spoon-fed them as they were not ready when they consulted me..."

Mentee 3: “...My mentors' approach was spoon-feeding. They also made use of feedbacking as an approach..."

- Modelling and feedbacking

Mentee 3: “...My mentors' approach was spoon-feeding. They also made use of feedbacking as an approach..."

Mentor 2: "...I closely supervised them as they were not attentive. I did modelling and feedbacking; and it was effective..."

Mentee 1: “...Their supervision is effective. They modelled the tasks; so, I was attentive..."

Depending on the nature of the mentors and mentees, mentoring may be done in a compromise relationship. In this study, the mentor exuded close and rigid supervision with spoon feeding at the helm of modelling and feedbacking. Modelling involves the mentees observing the mentor engaged in the process of professional practice and can provide a useful means of demystifying the process and providing the individual with a template for their own work. Purportedly, feedback is part of the mentees' learning process because it comprises an evaluative quality or judgement by the mentor. For the mentor to learn from feedback, it must be clear, concise, and honest. This may sometimes mean that the feedback is critical and even confrontational. When provided in an instructional context, feedback might include a focus on how the mentor is dealing with instructional objectives and needs during the coaching process.

In this study, both modelling and feedback played a significant role in the success of the mentoring process. Mentor 2 recapitulated the modelling and feedbacking that he used among his mentees. Moreover, mentees 1 and 3 claimed that the feedbacks provided by their mentees were effective.

In view of the Transformational Learning Theory, the little teachers (mentors) influenced their mentees by their personal experiences from DepEd. This happened in a dialogic manner and self-reflection through modelling and feedbacking under social reconstruction [7]. Mentee 3 recalled his experiences and understanding about peer mentoring and realized further that it is a good strategy. Based on his reflection, he said that he will eventually employ it in their future teaching.

\subsection{Factors hindering the efficacy of the mentoring program}

\subsubsection{Readiness of mentees and mentors}

Learning is an invite to come across learning that recalls the readiness of both the teacher (mentor) and the learner (mentees). In this study, the teacher is the little teacher while the learners are the mentees of the little teachers. As applied in peer mentoring process, both of them should complement each other as they try to build a reciprocating relationship that maximizes their potentials in achieving their goals-to teach science in the secondary schools for the first time.

In view of the Law of Readiness of Thorndike [27], it is claimed that learning is not automatically instilled if the recipient is not prepared for the tasks. Hence, the learners (mentees) start their learning from their personal relevant experiences and mental schema. Furthermore, the Schema Theory posited that the learners come to every learning task with a network of organized and interconnected ideas. Conversely, learners who are ready for the learning tasks are most likely to retrieve useful information in accomplishing their tasks [35].

The concept of learning deeper and learning together in peer mentoring spurs the idea that both parties should be ready in their tasks. When both parties are ready, the mentor may introduce interventions that will scaffold the learning tasks that will transcend the learning variable and atmosphere. This cultivates the spirit of collaboration and optimum learning between the mentor and mentee [16], [36]. Mentors 2 and 3 recalled that both parties should be ready for the tasks for it to be successful although Mentees 1, 2, and 3 claimed that their mentors must be ready enough for their tasks while Mentors 1 and 4 claimed otherwise.

The following transcripts from the informants qualify the claim of this study that the readiness of both the mentees and mentors affect the outcomes of the mentoring process: 
Mentee 1: "...Perhaps, it is their readiness as they were not sure of certain concepts (sometimes) as they might not have encountered it yet (pertaining to the concept). We took us so long in one of the tasks as my mentor was not familiar to it ..."

Mentee 2: "...Perhaps, it is their readiness of which I understand it well. They are still students and I believe they still lack the mastery..."

Mentee 3: "...Perhaps, it is the readiness of the mentors. One time, we brainstormed and researched at the same time as they were not sure of the concept. So, we exchanged ideas..." Mentor 3: "...Both parties must be ready. Sometimes, they came to me with nothing. So, I got no choice but to spoon-feed them ..."

Mentor 4: "...There were times that they were not ready for the tasks: so, it took us so long...."

Mentor 1: "...I really pushed them well. At times, I spoon-fed them as they were not ready when they consulted me..."

Mentor 2: "...Readiness of both parties is needed as the tasks are in partnership..."

\section{CONCLUSION}

Mentoring program as outlined by theorists and educationists involves the indulgence of both mentors and mentees. As such, mentors in the mentoring process need to be approachable and accommodating. On the other hand, mentees in the mentoring process need to be responsible with their learning task coupled with learning initiative. When mentors and mentees complement each other, the mentoring process provide enjoyable learning encounters, collaborative learning sessions, open and barrierfree communication, and close and rigid supervision through spoon feeding, modelling, and feedback are some of the perceived characteristics of an effective mentoring program. Furthermore, the readiness of both mentors and mentees is paramount to the success of the mentoring program, i.e., innovative intervention and scaffolding techniques may be drawn and implemented.

\section{REFERENCES}

[1] J. Campit, J. Cayabyab, and E. Galas, "The effect of peer tutoring on the achievement of students in discrete structures," Asia Pacific Journal of Multidisciplinary Research, vol. 3, no. 5, pp. 8-12, 2015.

[2] K. P. King, Bringing Transformative Learning to Life. Marlabar, FL: Krieger, 2005.

[3] D. Lecorchick, J. Maynard, M. Morin, S. Nichols, B. Peterson, and E. Ruesch, "School-based mentoring program: High school students' mentor elementary students," The Elementary STEM Journal, vol. 14, no. 2, pp. 18-21, 2018.

[4] J. Preston, M. Ogenchuk, and J. Nsiah, "Peer mentorship and transformational learning: PhD students' experiences," Canadian Journal of Higher Education, vol. 44, no. 1, pp. 52-68, 2014.

[5] S. Abegglen, T. Burns, and S. Sinfield, "The power of freedom: Setting up a multimodal exhibition with undergraduate students to foster their learning and help them to achieve," Journal of Peer Learning, vol. 9, pp. 1-9, 2016. [Online]. Available: https://ro.uow.edu.au/ajpl/vol9/iss1/2.

[6] E. McIntosh, "Working in partnership: The role of peer assisted study sessions in engaging the citizen scholars," Active Learning in Higher Education, vol. 20, no. 3, pp. 233-248, 2017.

[7] E. W. Taylor, "Fostering transformative learning," In J. Mezirow and E. W. Taylor, Eds., Transformative learning in practice: Insights from community, workplace, and higher education. San Francisco, CA: Jossey-Bass, 2009, pp. $3-17$.

[8] T. J. Carter, "The importance of talk to midcareer women's development: A collaborative inquiry. Journal of Business Communication, vol. 39, no. 1, pp. 55-91, 2002, doi: 10.1177/002194360203900104.

[9] J. Mezirow, Learning as Transformation: Critical Perspectives on a Theory in Progress. San Francisco, CA: Jossey-Bass, 2000.

[10] J. Mezirow and E. W. Taylor, Transformative Learning in Practice: Insights from Community, Workplace, and Higher Education. San Francisco, CA: Jossey-Bass, 2009.

[11] L. Hoshmand, "Narratology, cultural psychology, and counselling research," Journal of Counselling Psychology, vol. 52, no. 2, pp. 178-186, 2005.

[12] M. Carcary, "The research audit trail-enhancing trustworthiness in qualitative inquiry," The Electronic Journal of Business Research Methods, vol. 7, no. 1, pp. 11-24, 2009.

[13] K. Malterud, "Qualitative research: Standards, challenges, and guidelines," The Lancet, vol. 358, pp. 483-488, 2001, doi: 10.1016/S0140-6736(01)05627-6.

[14] L. Nowell, J. Norris, D. White, and N. Moules, "Thematic analysis: Striving to meet the trustworthiness criteria," International Journal of Qualitative Methods, vol. 16, no. 1, pp. 1-13, 2017.

[15] Z. Giannone, M. Gagnon, and H. Ko, "Mentorship as a career intervention: An evaluation of a peer-mentoring program with Canadian University Psychology students," Canadian Journal of Career Development, vol. 17, no. 2, pp. 4-24, 2018. 
[16] S. K. Ragavan, "Peer mentoring for international students in a UK law school: Lessons from a pilot case study," Innov. in Educ. Teach. Int., vol. 51, no. 3, pp. 292-302. 2013, doi: 10.1080/14703297.2013.785254.

[17] L. S. Vygotsky, Mind and society: The development of higher mental processes. Cambridge, MA: Harvard University Press, 1978.

[18] A. Cropper, "Mentoring as an inclusive device for the excluded. Black students experience of a mentoring scheme," Social Work Education, vol. 19, no. 6, pp. 597-607, 2000.

[19] K. Griffiths, F. Kopanidis, and M. Steel, "Investigating the value of a peer-to-peer mentoring experience," Australasian Marketing Journal, vol. 26, no. 2, pp. 92-98, 2018, doi: 10.1016/j.ausmj.2018.05.006.

[20] R. Hall and Z. Jaugietis, "Developing peer mentoring through evaluation," Innovative Higher Education, vol. 36, no. 1, pp. 41-52, 2011.

[21] B. Kensington-Miller, "Peer mentoring: stories of three mathematics teachers," Teacher Development, vol. 15, no. 3, pp. 293-304, 2011, doi: 10.1080/13664530.2011.608510.

[22] M. Graven, "Investigating mathematics teacher learning within an in-service community of practice: The centrality of confidence," Educational Studies in Mathematics, vol. 57, no. 2, pp. 177-211, 2004

[23] A Lieberman and D. P. Mace, "The role of 'accomplished teachers' in professional learning communities: Uncovering practice and enabling leadership," Teachers and Teaching: Theory and Practice, vol. 15, no. 4, pp. 459-70, 2009.

[24] G. Crisp and I. Cruz, "Mentoring college students: a critical review of the literature between 1990 and 2007," Research in Higher Education, vol. 50, pp. 525-545, 2009, doi: 10.1007/s11162-009-9130-2.

[25] M.L. Leung and T. Bush, "Student mentoring in higher education: Hong Kong Baptist University," Mentoring \& Tutoring: Partnership in Learning, vol. 11, no. 3, pp. 271-286, 2003, doi: 10.1080/1361126032000138319.

[26] A. Bandura, Social Foundations of Thought and Acton: A Social Cognitive Theory. New Jersey: Prentice Hall, 1986.

[27] A. Karadut, "Effects of E. L. Thorndike's theory of connectionism rudiments on developing cello playing skills for beginners," Procedia - Social and Behavioral Sciences, vol 69, pp. 298-305, 2012, doi: 10.1016/j.sbspro.2012.11.413.

[28] M. Bakhtin, The Dialogic Imagination: Four Essays. Austin, Texas: University of Texas Press, 1981.

[29] E. Turner, "Coaches' views on the relevance of unconscious dynamics to executive coaching," International Journal of Theory, Research, and Practice, vol. 3, no. 1, pp. 12-29, 2010.

[30] D. Gray and P. Jackson, Coaching Supervision in the Historical Context of Psychotherapeutic and Counselling Models: A Meta-Model. Maidenhead: OUP McGraw-Hill Education, 2012

[31] D. Gray, "Principles and processes in coaching evaluation," International Journal of Mentoring and Coaching, vol. 2, no. 2, pp. 21-35, 2004

[32] P. Hawkins and R. Shohet, Supervision in the Helping Professions. London: Buckingham Open University Press, 2000.

[33] D. Gray, "Towards a systematic model of coaching supervision - some lessons from psychotherapeutic and counselling models," Australian Psychologist, vol. 42, no. 4, pp. 300-309, 2007.

[34] H. Armstrong and M. Geddes, "Developing coaching supervision practice: An Australian case study," International Journal of Evidence Based Coaching and Mentoring, vol. 7, no. 2, pp. 1-17, 2009.

[35] J. Eby and D. Martin, Reflective Planning, Teaching, and Evaluation for the Elementary Schools: A Relational Approach. Ohio: Merril/Prentice Hall, 2001.

[36] A. Antonio, "The influence of friendship groups on intellectual self-confidence and educational aspirations in college," Journal of Higher Education, vol. 75, no. 4, pp. 446-473, 2004. 